\title{
THE EFFETCS OF TECHNOLOGICAL DEVELOPMENT AND ARTIFICIAL INTELLIGENCE STUDIES ON MARKETING
}

\section{DOI: 10.17261/Pressacademia.2015312948}

\section{Cuneyt Dirican ${ }^{1}$}

${ }^{1}$ Istanbul Arel University. cuneytdirican@arel.edu.tr

\section{Keywords}

Robotics, artificial intelligence, marketing, CRM, technology, customer relations.

JEL Classification

M10,M20,M30

\begin{abstract}
The use of Artificial Intelligence and Robotics at the Marketing and the overview of the impacts on customer relations will be highlighted within the paper. Internet, mobile technology, electronics, nanotechnology, advances in digital world has accelerated much more mechatronic work today. In the last World Economic Forum, Robotics and Artificial Intelligence found an important place and Roubini, Stiglitz participated for such effects and debates with their articles. The unemployment rate, the Philips Curve, Purchasing Power Parity, GDP, inflation, money, management, accounting, and so on will face significant changes with these developments in the coming years. One of the most significant impacts is expected to occur in Marketing. Analytical and Operational CRM, customer relationship management, sales, distribution channels, product costs and pricing, data mining, will be affected by the behavioral change arising by the Robotics and Artificial Intelligence developments. This article will put the conceptual and theoretical work of these new developments.
\end{abstract}

\section{TEKNOLOJIK GELIŞMELERIN VE YAPAY ZEKA ÇALIŞMALARININ PAZARLAMA BILIMINE ETKILERI}

\section{Anahtar Kelimeler Robotik, yapay zeka, pazarlama, CRM, teknoloji, müşteri iliş̧kileri.}

\section{ÖZET}

Sanayi Çağı'na giriş ile beraber insanlık mekanizasyon başlangıcı ile seri üretime geçmişti. Internet, mobil teknolojiler, elektronik, nano teknoloji, digital alanlarındaki gelişmeler mekatronik çalışmaları günümüzde daha çok hızlandırdı. Son World Ekonomik Forum'da Robotik ve Yapay Zeka önemli bir yer buldu ve Roubini, Stiglitz gibi ekonomistler de ekonomi ve iş dünyası üzerine gerçekleşecek etkiler için bu tartışmalara makaleleri ile katıldılar. İşsizlik oranı, Philips Eğrisi, Satınalma Gücü Paritesi, GSYIH, enflasyon, para, yönetim, muhasebe, vb. bir çok başlıkta önemli değişimleri bu gelişmeler ile önümüzdeki yıllarda gözlemlemek söz konusu olacaktır. En önemli etkilerden birinin ise, işletmenin en önemli fonksiyonlarından pazarlama boyutunda yaşanması beklenmektedir. Analitik ve Operasyonel CRM, müşteri ilişkileri yönetimi, satış, dağıtım kanalları, ürün maliyet ve fiyatlamaları, veri madenciliği gibi pazarlama başlıklarında, Robotik ve Yapay Zeka ile bir çok davranışsal değişimi dünya örnekleri ile aktarmayı hedefleyen ve bu konuda yaklaşımları içeren bir çalışma hedeflenmektedir. Pazarlama bilimi ve müşteri ilişkilerinin geleceği üzerine, bu alandaki gelişmeler ile bir akademik çalışmanın gereksiniminden hareketle, kavramsal ve kuramsal çalışma ile Pazarlama Biliminde Yapay Zekanın ve Robotik kullanımına ve yaratacağı etkilere bakış tutmayı amaçlamaktadır. 


\section{GiRiş}

Lehman Brothers Yatırım Bankası'nın 2008'de batması ile başlayan "Global Finansal Kriz" ile beraber ekonomi ve finans başlıklarında bir çok kuramın deneyimlendiği veya revize edilmek zorunda kalındığı yeni bir çağa girilmiş bulunuyor. Keynes'in "Likidite Tuzağı Teorisi” (Baydur ve Süslü, 2011), 2008'den bu yana sıfıra yakın politika faizi seviyeleri ile, paranın değerini yönetmek ve fiyat istikrarını sağlamak ile görevli Merkez Bankaları tarafından, özellikle 2008'den bu yana en önemli para politikası aracı olarak kullanılıyor. Para arzı ve parasal taban genişlemesi noktasında ciddi bir rol oynayan Merkez Bankaları bu şekilde düşük faizlerle ekonomik toparlanmaları, işsizliğin ve dış ticaret açıklarının azalması ile dengeyi, fiyatlar genel seviyesinde artış ile canlanmayı, sağlamaya çalışıyor.

Sermaye hareketleri, döviz kuru sistemleri, ödemeler bilançosu, türev ürünler, davranışsal finans, portföy yönetimi ve teorisi, BASEL ve sermaye yeterliliği, internet bankacılığı, dağıtım kanalları, kredi kartları gibi ana başlıklar ile beraber Bretton Woods ve Smithsonian Anlaşmalarından bu yana finansal hizmetler sektöründe bir çok yenilik ve değişiklik yaşandı. Paranın elektronik formlarda, digital ekonomi çağı ile beraber transformasyona uğraması ve arzının liberalleşmesi dünyadaki önemli merkez bankalarının global finansal krize cevap verebilmek adına likiditeyi devamlı arttırıyor olması, ödeme sistemlerinin hızla gelişmesi ve finans kurumu olmayan finansal aracıların piyasalarda aktif rol almaya başlaması ışığında başta bankacılık ve finansal hizmetler sektörü olmak üzere tüm şirketlerin yeni dünyanın teknolojilerine daha hızlı adapte olması zorunluluğu doğdu. Özellikle, globalleşme, digital uygulamalar, internet ve mobil, CRM alanındaki çalışmalar, bilgisayarların gelişimi ile yeni bir evreye giren finansal hizmetler, artan kaydi para arzı karşısında yeterli üretimi ve risk yönetimini beraberinde aynı parelelde getiremeyince, 2000'li yıllardan sonra dünyada finansal hizmetler başta olmak üzere bir çok sektörde ve sonrasında ülke ekonomilerinde ve hazinelerinde karlılık, sürdürülebilirlik başıılarında olumsuz sonuçlar yarattı. 2008 ile birlikte kırılma yaşayan ekonomiler üzerinden finans alanında ve işletme dalında bir çok şirket artık daha fazla kar edebilmenin, daha çok pazara ve müşteriye ulaşabilmenin, elde tutabilmenin, rekabetteki gelişimlere cevap verebilmenin, maliyetleri kısarken satışları arttırabilmenin yollarını daha çok sorguluyorlar. Sektörler ve şirketler üzerindeki bu baskılar pazarlamayı ve müşteriyi daha önemli hale getiriyor. Pazarlama ve satış kavramlarını ise daha yeni teknolojiler ve değişen müşteri davranışları ile çok daha farklı gündemler bekliyor.

1990'lardan sonraki globalleşme ve internet ile mobilin etkileşimi ile müşteri taleplerinin ve beklentilerinin değişimi, CRM alanındaki teknolojik gelişmeler, sosyal medya, iletişim formatlarının ve şekillerinin değişmesi ile bu süreç daha da hızlanmak durumunda kaldı. Yapay zeka, semantik çalışmalar, robotik ve mekatronik gelişmeler, big data, cloud computing, neural (sinir) ağlar, veri madenciliği ve giyilebilir elektronikler, nano ve genetik bilim, hologram, nesnelerin interneti gibi yeni ana teknolojik trendler ekonomileri, sektörleri, şirketleri, karar verici ve çalışanları yakından etkileyecek. 


\section{LITERATÜR ANALIZi}

Bu yeni teknolojilerin iş hayatında gündeme gelmesi 2010'lu yıllardan sonra ivme kazandı.

Robotik, mekatronik, bulut teknolojisi ve yapay zekanın tanımları konu ile ilgili tartışma ve bulguları irdeleyebilmek adına daha önceki çalışmalardan aşağıdaki şekilde aktarılmıştır :

Robotlar ilk olarak 1921 yılında Prag'da tanıtılmıştır (Bischoff ve Guhl, 2010) ve eski Pers Türk düşünürü İbn Sina'nın çalışmalarına atıfta bulunularak, insan benzeri antropomorfik bir görünümleri olduğu ifade edilmiştir. Robotik tanımı (Murphy, 2000) ise şu şekilde verilmektedir:

"Robotik akıllı bir robot ya da özerk işlev görebilir mekanik bir yaratıktır."

Yu ve Kodama (Yu, 2008; 1986 Kodama) ise Mekatronik dalını şu şekilde tanımlanır :

"1960 sonlarında Japonya'da icat edilen bir terim olarak, hassas mekanik mühendisliği, elektronik mühendisliği, yazılım mühendisliği, ürün ve üretim süreçlerinin tasarımı ile düşünme sistemlerinin sinerjik birleşimidir."

"Mekatronik, mekaniğin ve elektroniğin birleşimidir."

Yapay Zeka bilgisayarlar ve uygulamalar, insanın iyi olduğu birçok alanda etkileşim kurabilen ve hareket edebilir bilimsel çalışmalar olarak tanımlanmaktadır (Rich, 1985).

ABD'de National Institute of Standards and Technology's (NIST) cloud computing çalışma tanımı (NIST Özel Yayın 800-145) kısaca şu şekilde anlamlandırılacak halde vermiştir :

"Bulut Teknolojisi (Cloud computing), bilgi, veri, dosya veya kaynakların paylaşımını kolaylaştıran, olanak sağlayan bir ağ tabanlı ya da internet tabanlı depolama ortamıdır."

Hologram veya kayıt, bir dalganın orta çizgisi ile tepe noktası veya dip noktası arasındaki açıklığın, şeffaf gönderilen bir ışık hüzmesi ile yeniden oluşturulması işlemidir (Enloe vd., 1966).

Yapay Sinir Ağlar, büyük veri, internet, anlamsal arama, yapay zeka ve cloud computing dallarının bir kombinasyonu olarak özetlenebilir. "Yapay Sinir Ağları" öğrenerek ve ezberleyerek ilgili örneklerle desteklenmesi halinde geçerli ve doğru cevapları üretebilir ve çok büyük miktarda veri içerisinden doğru sonuca ulaşabilir. (Taylor, 1993).

Stephen Hawking'in "Yapay Zeka" insanlığın sonunu getirebilir savına rağmen (Lewis, T. LiveScience.com, 2015), robotların, yapay zekanın ekonomi ve iş hayatındaki yeri her geçen gün artıyor. Hawking'e, Microsoft CEO'su Bill Gates ve SpaceX ile Paypal kurucusu CEO Elon Musk'ın eşlik etmesi ve konuya dikkat çekmesine rağmen (Griffin, 2015), teknolojik gelişmelere paralel olarak mekatronik, digital, mobil, genetik ve tıp biliminin ilerlemesi ile yakın dönemde bu iki kavrama dayanan gelişmeleri işletme, ekonomi, pazarlama ana bilim dallarında sıkça duymak söz konusu olacaktır. Bu doğrultuda, Pazarlama Bilimi ve Müşteri İlişkileri üzerine olası etkilerine değinmeden önce, konu şu şekilde özetlenebilir :

Film sektörü bir çok alanda genelde elindeki senaryo ve teknik imkanlar ile gerçek hayatın önünde gitmekte ve hatta bazen yön vermektedir. Bu konuda, ABD film endüstrisinin temsil edildiği yer Hollywood'da konunun farklı boyutları ile irdelendiği örnekler 
bulunmaktadır (Faden, 2001). Örneğin, Yapay Zeka, Teminatör veya IRobot filmlerindeki gibi robotların ele geçirmek istediği ve insanlıkla savaştığı senaryolar dikkate alındığında veya robotların asker olarak savunma sanayisinde yer alacağı düşünüldüğünde (Singer, 2010), Asimov'un 3 temel kuralına uymayan durumların gerçek olması halinde mücadeleyi kimin kazanacağı bilinmemekle birlikte, bu senaryoların öncü etki, gösterge ve sonuçlarının iş dünyası üzerinden ekonomiye, işletmelere, işletmelerin üretim, pazarlama gibi temel fonksiyonlarına yansımalarını, yakın gelecekte bugünkü kavramların çok ötesinde farklılık ve değişimler ile gözlemleyeceğimiz ve deneyimleyeceğimiz savını iddia etmek mümkündür (Matthews, 2013). Bugün kullandığımız buzdolabı, çamaşır makinesi, televizyon, mutfak robotu gibi akılsız, düşünmeyen ve duygulara sahip olmayan cihazların ileride duygusal ve yapay zekaya sahip olması halinde yaratabileceği sorunlar bunlardan en basitidir (Brooks, 2002). Google'ın kendi kendine gidebilen arabası (Markoff, 2010) veya Apple Iphone akıllı asistanı SiRi, Android telefonların akıllı asistan versiyonu CEYD-A yapay zeka ve robotların iş hayatındaki ve pazarlamadaki birer öncü göstergesidir. Müzik endüstrisindeki hologram show ve konserler bir diğer boyuttan pazarlamanın gidebileceği sınırları göstermektedir (Leuski, 2006)

\section{YÖNTEM VE TARTIŞMA}

Pazarlamanın ve Müşteri İlişkilerinin geleceği üzerine kavramsal ve kuramsal bir akademik çalışmanın gereksiniminden hareketle, bu çalışma hipotetik olarak bu konulara farklı bir bakış tutmayı ve sonraki daha kapsamlı çalışmalara kavramsal ve kuramsal olarak önermelerle bir baz olmayı amaçlamaktadır. Süreç bazlı önermelerden yola çıkılarak gelecek çalışmalarda anket yöntemleri, analitik modellemeler üzerinde test edilmesi ile desteklenmesi planlanmaktadır.

Bu doğrultuda ; Genel İşletme bilim dalında ve alt dallarında, Pazarlama Bilimi ve Müşteri îlişkileri de dahil olmak üzere olası etkileri ile beraber bulgular ve genel hipotetik kavramlar şu şekilde özetlenmektedir.

Capon ve Glazer teknoloji ve pazarlamanın entegrasyonu dahilinde, firmaların bir teknoloji portföyü yaratmasının ve optimum teknoloji seti kullanmasının faydalarına değinmişlerdir (Capon ve Glazer, 1987). Pazarlama ile ilişkisine detaylı olarak geçmeden önce, teknolojik gelişmelerin karşısında üretim faktörlerinden emeğin durumunu değerlendirmek gerekmektedir. Mekanizasyon kapsamında seri üretimde, başta otomotiv veya beyaz eşya sanayinde primitif robotlar üretim bandında yer almaktadır. Henüz komutlarla çalışan ve yapay zekaya sahip olmayan bu robotlar basit montaj işlemlerini gerçekleştirmektedir. Ancak, mekanik, elektronik ve bilgisayar teknolojilerini kullanarak ürünlerin, sistemlerin ve proseslerin performansını zenginleştiren, bütünleştirici disiplin olan mekatronik ile akıllı makine ve cihazları, akıllı ev ve şehir sistemleri ve akıllı süreçleri içeren tasarım ürünleri geliştikçe, üretim ve işletmenin diğer fonksiyonel aşamalarında yapay zeka ve mekatronik / robotik çözümleri daha çok görmek söz konusu olacaktır. (Algaç, K., 2010)

Bu konuya bir örnek olarak, Volkswagen firmasının emekli olan işçilerin yerine daha çok robot kullanacağını belirten haberi vermek mümkündür (Phillips, 2014). Robotların yükselişi veya inovasyon ile işsizlik başlıklarını değerlendirdiğimizde (Roubini, 2014 ; Stiglitz, 2014), otomobil üretim maliyetlerine olumlu yansıyacak bu gelişme, onu satın alacak işgücü kesiminin iş ve gelir kaybına sebep olduğunda, diğer bir üretim faktörü 
sermayedar (girişimci ve sermaye) nasıl etkilenecek sorusu üzerinden, GYSiH büyümesine, Milli Gelire, Satın Alma Gücü Paritesi'ne kadar bir çok alana etki edecektir.

Bu konuda, ise Keynes'in görüşü, Klasik iktisatçılardan çok farklı olmayarak, nettir (Fisunoğlu ve Bilge 2009). Buna göre, işsizlikte yaşanacak önemli dereceki bir azalma, reel ücretlerde de bir azalmayı getirecek, parasal ücretlerdeki bu düşüş ise işsizliği daha da şiddetlendirecektir. Ücretlerdeki indirimler, toplam talepte bir azalmaya yol açacak ve bundan hareketle satışlar ve karlılık üzerinde sıkıntı yaşanması nedeni ile, ücretlerin azaltılması yönünde işletmeler tarafından izlenen politikalar, sendikalar veya sivil toplum kuruluşları ile organize olmuş işgücünün tepkileri ile karşılaşacaktır. Bu şekilde artacak sosyal hareketler, grevler, lokavtlar ve çatışma ortamları ile belirsizlik ortamının ve ücret indirimlerinin faiz oranları ve yatırımlar üzerindeki olumsuz etkileri söz konusu olacaktır. İyimserlik ve karlılık beklentisi olmadığı durumda ise iktisadi faaliyetler artmayacaktır (Ardor ve Varlık, 2012: 197-200).

İşizliğin az olduğu ekonomilerde enflasyon yükselir diyen "Philips Eğrisi" dikkate alındığında, günümüzde global ve gelişmiş ekonomilerde yaşanan tersi senaryoda yani enflasyon yerine deflasyonist bir süreçte, ekonomik durgunluktan çıkmak için sürekli para arzını arttıran gelişmiş ekonomiler ve Merkez Bankaları açısından başka bir boyuttan farklı sonuçlar doğuracaktır. Özellikle, birçok ülkede başta ABD olmak üzere Merkez Bankaları ülke hazinelerinin finansörü durumuna gelmişlerdir. Amerikan Hazinesinin doğrudan veya dolaylı olarak çıkardığı ve garantör olduğu tahvillerin Amerikan Merkez Bankası FED'in bilançosunun \%95'ini oluşturması noktasında, gelişmiş Merkez Bankalarının bağımsızlığının tartışılması ayrı bir gereklilik olarak görünmektedir (federalreserve.gov, 2015). Yatırım ve işsizlikte yaşanacak sıkıntılar ile daha çok borçlanmak zorunda kalacak hazinelerin, bunların faiz ve anapara geri ödemelerini gerçekleştirememesi ve borçlarını ödeyememesi durumunda, 1930'da kurulan Merkez Bankalarının Bankası Bank for International Settlement (BIS) dahil olmak üzere bir çok Merkez Bankası'nın batması olasılığını da gündeme getirecektir (Howden, 2009 ; Buiter, 2008). Bu noktada, son Yunanistan örneği, IMF'e borçlarını ödeyememesi olasılığı bu konudaki beklentileri güçlendirecek şekilde, ötelenmiş bir riske açıklık durumu doğurmaktadır (Habertürk, AA, 2015).

İnsan Kaynakları mı, Kıymetleri mi, Personel Yönetimi mi tartışmaları profesyonel iş hayatında tartışılmaya devam ederken, artık robotlar ve yapay zeka bir çok alanda ekonomi ve gündeme gelmektedir. Roubini ve Stiglitz'in (2014) çalışmalarında değindiği bu başııklar, robotların yükselişi veya inovasyon ile işsizlik, Pazarlama Bilimi'ne de yakından etki edecek ve farklı sonuçlar doğuracaktır. Pazarlama Bilimi'ne olan doğrudan etkilerine geçmeden önce iş hayatına yansımalarına örnek verirsek;

Kurumsal hayatta, günümüzde, ünvan ve görev tanımı olarak teknolojik gelişmelere paralel olarak rastladığımız, digital pazarlama veya sosyal medya yöneticisi, bilgisayar operatörü, analitik CRM uzmanı, bilgi işlem network uzmanı gibi iş tanımları daha çok ön plandayken, yapay zeka ve mekatronik / robotik ile ilgili çok farklı başlıkların hayatımıza girmesinin yakın olduğunu (Tarhan, 2010), Amazon.com'un ürünlerin dağıtım kanalı maliyetlerini düşürmek için istihdam ettiği drone kullanıcısı gibi yeni mesleklerden görebilmek artık mümkündür (Kharpal, 2015). İnsan kaynaklarındaki etkiler sadece bunlarla sınırlı mı olacaktır? 
Pazarlamada ve insan kaynaklarındaki etkiler bunlarla sınırlı mı olacaktır?

Birçok başlıkla bu soruyu olası etki ve sonuçları ile irdelemek mümkün olacaktır. Çalışan devir oranı yüksek firmalarda ve sektörlerde, örneğin perakendede, binlerce satış ve reyon sorumlusunun özgeçmişi incelemek için işe alım uzmanı çalıştırılmayacak gibi kuramsal bir yaklaşımı iddia etmek artık çok zor olmamaktadır. Veya, para ve fatura tahsil etme, ödeme fonksiyonu ağırlıklı çalışan banka gişeleri, market kasalarında çalışanların robot olduğu bir durumda, (ATM terminolojisinin açılımının Automated Teller Machine olduğu dikkate alındığında) satın alma departmanının veya bilgi işlemin yönetebileceği bir dünyada insan kaynakları departmanına gerek kalmayabilecek bir süreç beklenmektedir. Robotlar için maaş ödemesi söz konusu olmayacağından, muhtasar vergisi, SGK primi, emeklilik kıdem tazminatı da olmayacaktır. Bu doğrultuda iş kanunu maddelerini yorumlayacak bir özlük hakları uzmanına gerek kalmaması veya insan kaynakları bölümlerinde muhasebe ilkelerine ve amortisman esaslarına daha fazla hakimiyet gereksinimi söz konusu olacaktır.

Bankacılık sektörünün hızla gelişen mobil, internet ve digital teknolojilere adaptasyon sürati dikkate alındığında, önceki paragraftaki bu hipotezlerin gerçekleşme olasılığının yüksekliğini göstermek mümkündür.

Teknolojideki 1990 yılından bu yana yaşanan hızlı gelişmeler ve inovasyon, internet, mobil ve CRM sistemler, Evrensel Bankacılık kavramı dahilinde, global ve küresel olarak bağlı bir dünyada, herhangi bir sınır ve engel kalmadan, bankacılık sektörü ve finansal hizmetlerdeki etkileri ve değişiklikleri net bir şekilde kanıtlamıştır. Elektronik Bankacılık aracılığıyla finansal hizmetler her geçen gün çok daha kolaylaşmaktadır. (Javadin ve Yazdani, 2005). Basel Komitesi elektronik kanallar aracılı̆̆ıyla etkileşime giren hem birey hem de kurumsal bankacılık müşterileri ve işlemleri için internet ve mobil bankacılık kapsamlı Elektronik Bankacılığı tanımlanır (Basel Bankacılık Denetleme Komitesi, 2003).

Bankacılık ve finansal hizmetlerde, güvenlik, eğitim, internet erişimi, gelir gibi konular internet bankacılığı kullanımını için her zaman bir endişe iken (Altan \& Karasioğlu, 2004; Bayrakdaroğlu, 2012), web ve mobil teknolojiler bankasız kesimler, mikrofinansman ile kadınlar ve start-up işletmeler ve ekonomik toparlanma için büyük fırsatlar sunmaktadır. Mobil bankacılık, mobil (fatura) ödemeler, mobil sigorta ve mobil para transferleri ile ülkelerin GSYiH artışının desteklenmesi ve G-20 ülkelerinin önem verdiği "Finansal Tabana Yayılma" (Financial Inclusion) için kullanımı her geçen gün artmaktadır (Mas \& Kumar, 2008). Bankacılık ve finansal hizmetler sektörü müşteri talebini karşılamak ve bu son derece yıkıcı değişiklikleri (Jayamaha, 2002) yönetmek için kendi çabalarıyla son on yılda bir kuantum sıçraması ile karşılık vermeye çalıştılar. Bankalar, Müşteri iliş̧kileri Yönetimi (CRM) Sistemleri, müşteri çağrı / kontak merkezleri, diğer dağıtım ve etkileşim kanalları, Net Promoter Score (NPS) gibi daha sofistike sistemlerle, tüketicilerin talep ve baskılarını öngörmek ve yönetmek, düşen müşteri sadakati ile başa çıkmayı mümkün kılmak için teknolojiyi yoğun bir şekilde kullandılar. NPS izleme sistemleri, Gizli Müşteri (Mystery Shopping) anketleri uygulanan bankaların karlılığı ve müşteriyi elde tutma yüzdeleri arttı. Bu çabalarla, finans kuruluşları ve bankalar daha sadık müşteriler yaratmak ve müşteri memnuniyetini ya da deneyimini geliştirmek ve arttırmak amacıyla, veri stratejisi ile bilginin kalitesini yönetmek, müşterileri ile daha hızlı iletişim sağlamak için yenilikleri daha fazla kullandılar (Amiri Aghdaie, Karimi \& Abasaltian, 2015). Bu çabalar sonucunda, bazı ünvan ve görev tanımları yok olurken, organizasyon şemalarında yeni kutucuklar açılmaya 
başlandı ve merkeze alınan karar mekanizmaları ile şubeler daha satış odaklı ve sayıca az kadrolar ile yönetilirken, sektörde düşük kalifiyeli işgücü yavaş yavaş yerini teknolojiyi daha iyi kullanan çalışanlara bıraktı. Benzer şekilde, karar mekanizmaları dahil bir çok alanda teknoloji insanın yerini aldı. Sermaye piyasalarında, özellikle Forex piyasalarda, bilgisayarların kendilerine verilen alım - satım emirlerini otomatik proses etmesi de bu anlamda yapay zeka uygulamalarının en basit şekli olarak karşımızda durmaktadır.

Şirketler, global kriz sonrasında maliyetleri en aza indirmek ve şirket değerini maksimize etmek için Porter'ın “Değer Yaratma ve Rekabet Avantajı Kuramı” (Porter, 1985) dahilindeki tek iki seçeneği takip ederek karlılığı ve sürdürülebilirliği kolaylaştırabilirler. İlk olarak, maliyetleri azaltmak ve verimliliği arttırmak. Yeni veya gözden geçirilmiş pazarlama ve satış süreçleri, dağıtım kanalları ile diğer üretim faktörlerinin verimliliğini ve üretkenliğini artırarak işletme, pazarlama maliyetlerini en aza indirmek ilk olasılıktır. İkinci olasılık ise yenilikçi ürünler ve kanallar ile pazarlama bileşenlerini kullanarak yeni trendlere göre daha fazla müşteri çekmek için inovasyon, AR-GE gibi imkanları kullarak satışları arttırmaya çalışmak ve malın \& hizmetin fiyatını yükseltmek. Bu noktada, teknoloji ve dijital platformların yanı sıra diğer pozitif bilimlerdeki gelişmeler, örneğin genetik, nano, psikoloji, uzay, tıp, mekatronik, robotik, yapay zeka, semantik, 3 boyutlu yazıcılar (3D), hologram, e-para ve elektronik finansal hizmetler işletmelerin gelişimi ve sürdürülebilirliği üzerinde çok büyük bir etkiye sahip olacaktır. Bu şekilde, alternatif dağıtım kanallarını 7/24 çalışacak ve faydalarını maksimize edecek şekilde, çalışma saatlerini bu yeni teknolojik imkanlarla uzatarak, iş süreçlerinde verimliliği ve üretkenliği artıracaktır. Benzer şekilde, CRM'in müşteri davranışlarını reaktif olarak sonradan ölçme durumunu, semantik olarak bulut teknolojisi ile işlem anında gerçekleştirebilecek ve akıllı uygulamalar ile müşteriye anında değer önerisi sunarak, geri bildirimlerini ölçme imkanına sahip olabilecektir.

Müşteri deneyimlerinin robotlar karşısında nasıl değişeceği ve gelişeceği noktasında araştırmaların arttırılması ile gelecek sosyo-kültürel değişimlere hazır olunması imkanı bulunmaktadır. Hologram müşteri temsilcilerinin rakip firmanın mağazasında satış faaliyetlerini gerçekleştirmesi imkanı, Amazon.com gibi kurye maliyetlerini düşürmek için drone'ları kullanan firmaların, kargo firmalarının maliyetine ve zaman kaybına katlanmadan mal gönderimlerini gerçekleştirmesi noktasında dağıtım kanallarından acenta, bayilik gibi sistemlerin geleceğine veya elektronik ticarette pazarlamanın gelişimine kadar bir çok noktada, pazarlama ve satış kitapları ile yönetim kitaplarının da yenilenmesini gerektirecek yenilikler işletmelerin ajandalarında yer kaplayacaktır. Yapay sinir ağları ile müşteri gibi düşünen robotlar satış noktalarında hizmet verecektir.

3D yazıcılar ile, oda büyüklüğündeki bilgisayaların artık cebe girdiği dikkate alındığında, kişisel ev tipi üretimler başladığında, şirketlerde sürdürülebilirlik nasıl sağlanacağı, yeni pazar bulma, katalog ile direk pazarlama gibi unsurlar, self servis satış kavramı değişikliğie uğrayacaktır. Örneğin, IKEA'nın ya da mukavva, seramik veya cam sektörünün nasıl bir geleceğe hazır olması gerektiği noktasında, kartuş dolum hizmetlerinin her türlü kimyasal veya maden için yapılabilmesi halinde üretim bantları, depolama, lojistik, yatırım geri dönüşleri (ROI) ne olacaktır sorusu beyaz yakalı profesyonellerin cevaplaması gereken yeni sorular arasında bulunmaktadır. Pazarlamada 4P ile beraber müşteri deneyimi, segmentasyon, pazarlama karması, veri madenciliği, CRM, pazarlama iletişimi, reklam, 
sosyal medya, fiyatlama gibi konularda radikal dönüşümlerin beklenmesi kaçınılmaz olacaktır.

\section{BULGULAR}

20. Yüzyılda mekanizasyon ile başlayan süreç, yüzyılın sonunda bilgisayar teknolojilerinin gelişimi ile bilginin önemini ortaya koydu ve mobil, internet gibi yeni teknolojiler ile ivme kazandı. Drucker'ın 1993 yılında tanımladığı gibi, bilgi artık üretim faktörleri arasındaki en önemli bileşendir. Bundan hareketle, bilgi ve değer zincirlerine tanımlanmış şirketlerin rekabette yer alacağı ve geleceğin kazananlarının bu şirketler olacağını tanımlamış ve bundan hareketle Kotler ve Achrol pazarlamada önemli değişimlerin teknoloji ve bilgi üzerinden gerçekleşme durumunda olduklarını analiz etmişlerdir (Achrol \& Kotler, 1999). 21. Yüzyılda ise, yakınsama kavramı dahilinde farklı teknolojiler ve bilim dalları birbirleri ile etkileşime girmeye başladı. Bağımsı olarak ve birlikte, farklı dinamikler ve gelişmeler ışığında her geçen gün insan ve iş hayatına farklı bir ajanda ile yön vermekte ve etkilemektedir. World Economic Forum'da sadece robotlar ve yapay zeka ile ilgili ayrı bir başlık bulunmaktadır (WEF,2015).

Doğaldır ki, bugünün normlarında geçerli olan bu önerme ve hipotezlerimizin zaman içerisindeki trendler ile şekilleneceği doğal olarak aşikardır. Bu bilgilerden hareketle, Pazarlama'da Analitik CRM çalışmalarındaki bir çok alt başlığı birleştirerek, Pazarlama bilimi ile gelişen teknolojiler arasındaki ilişkiyi ve Yapay Zeka Pazarlamacılığı (Tarhan, U. İşveren Dergisi, 2010) uygulamalarına yönelik kavramsal ve kuramsal hipotezlerimizi aşağıdaki şekilde verebiliriz :

- Günümüzde önemli bir CRM başlığı olan Big Datayı saniyeler içinde proses edip, mağazaya veya şubeye gelen bir müşteriye "Müşteri Hayat Boyu Değeri - Life Time Value (LTV)" ölçümüne göre iterasyonla yapılan "Bir Sonraki En İyi ÜrünNext Best Product" değer önerisinin otomatik sunulması,

- Bulut Teknolojisi'nde (Clouddaki) tutulan "Net Promoter Score'a" bu değer önerisinin etkisi üzerinden gerçek zamanlı kampanya yönetimi sonuçlarının değerlendirilmesi,

- Müşteri segmentasyon çalışmalarında, bir çok kurumda belirli dönemlerde önceden tanımlı kural setleri dahilinde, alt veya farklı segmentler arasında geçişler ve müşteri göçleri yapılmaktadır. Yeni teknolojilerin eşzamanlı büyük verileri işleme kapasitesi dahilinde, segment geçişlerinin satış işleminin hemen sonrasında oluşan yeni müşteri veya portföy değerleri üzerinden eşanlı yapılabilmesi

- Değer önerisinin müşteri tarafından kullanım durumuna göre, müşteri segmentasyondaki davranışsal ve değer bazlı verilere bağlı olarak eş zamanlı olarak gözden geçirilmesi ve hizmet seviyesi ile satış sonrası servislerin otomatik olarak proses edilmesi,

- Müşteri Eğilim Analizlerinin semantik uygulamalar ile desteklenerek robotik bazlı dağıtım kanallarına eşzamanlı indirilmesi. Semantik Google, Yahoo gibi internet arama motorlarında web aramaları için kullanılan bir kelimedir ve yapay zeka arama tarafından kullanıcının niyetini ve sorgunun anlamını dikkate alarak, temel ihtiyacı ve kelimeleri anlar, aramalarını buna göre yapay zeka kullanımı ile yapar (Lolli, 2013). 
- Kanal bazlı fiyatlama ve satılan malın maliyeti çalışmalarının gerçek zamana yakın bir hızda proses edilmeye başlanması ve birebir özel yaklaşımlı fiyatların işlem anında müşteriye sunulması

- Müşterilerin alışveriş anındaki reyon davranışlarının ölçümlenerek, kasada ödeme anında indirim, fırsat gibi kampanya imkanlarının gerçek zamanlı sunulması

- Kampanya uygulamalarında analizlerin gerçek zamanlı yapılarak, kampanya bütçesi, performansı gibi takiplerin giderek kritikleşen pazarlama giderlerinin optimal yönetimine imkan sağlayacak şekilde gerçekleşmesi

Pazarlama başlığındaki diğer etkilere yönelik hipotezlerimiz ise özetle şu şekildedir :

- "Müşteri Deneyimi" sonuçlarına etkisine göre, yukarıdaki önermelerde yapılan bu değer önerilerinin işletmenin bütçe / gerçekleşme ile gelir tablosuna etkilerini gerçek zamanlı hesaplayıp, bir sonraki senenin stratejik planlamasının alternatif ekonomik verilere göre hesaplanması ve karar verici yöneticilerin önüne dashboard olarak sunulması,

- Satış sonrası hizmetlerde çağrı merkezi ve internet bazlı destek sayfalarında robotların müşteri taleplerini proaktif cevaplaması, (ki günümüzde bunlar uygulanmaktadır)

- Üretim bantlarında robotların çalışması ile düşmesi beklenen üretim maliyetlerinden hareketle, satılan malın maliyetlerindeki olumlu gelişmelerin, ürün fiyatına yansıması ve pazarlama bileşenlerinde bu gelişmelere paralel olarak olumlu yansımaların çoğalması,

- Daha önceki paragraflarda ifade ettiğimiz üzere, pazarlama alanında çalışan bir çok insanın görev tanımlarında değişiklik gereksinimi, görev yerlerinde değişiklik, işsiz kalmaları, bir çok yeni görevin yapay zeka ve robotlar tarafından gerçekleştirilmesi,

- Pazarlama iletişiminde sosyo kültürel ve sosyo ekonomik boyutların daha çok teknolojik vurgu ile ön plana gelmesi, örneğin Arçelik Çelik, Citroen Creative Technology.

- Sosyal medya uygulamalarının hologram teknolojisi ile birleşmesi,

- Üniversitelerin ve yükseköğretimin de bu gelişmelerden etkilenmesi söz konusudur. Yeni bilimler ve alt bilimler tanımlanmak durumunda kalınacak ve büyük olasılıkla yapay zekalı robotlar birçok bölümlerde akademik personelin yerini alması,

- Stiglitz'in belirttiği gibi düşük vasıflı insanların satın alma güçleri düştüğünde veya bilgiye ulaşmada ve çeşitli şekillerde veri işleme kolaylığına sahip olmaları halinde, lise, kolej veya üniversitelere gitme eğilimlerinde değişiklik olacaktır. 1900'lerde Sanayi Devrimi ile başlayan kalifiye işgücü ihtiyacı ile teknolojik gelişmeler arasındaki ilişkinin insan yerine yapay zeka, yapay sinir ağları ile yönetilmesi noktasında önemli farklar bulunmaktadır.

- Muhasebe tarafından konuya bakıldığında, şirketlerde personelinin kıdem tazminatı karşııkları ayrılmaya devam etmeli midir ya da hala insan kaynakları yöneticileri tarafından idare edilmek durumunda kalan robotlar için amortisman / itfa karşııı̆ının hesaplanması mı gerekmektedir. Şirketler bu yeni iş gücü kavramı için vergi ödeyecekler midir ? Özetle, bilançonun pasif tarafında mı, aktif tarafında 
mı robotların takip edileceğinden hareketle, Uluslararası Finansal Raporlama Sisteminin gözden geçirilmesi ihtiyacı bulunmaktadır.

- Şirketlerde performans ölçümü için Yeni Anahtar Performans Göstergeleri (KPI), yeni finansal analizler oranlar, müşteri deneyimlerini ölçmek için yeni Net Promoter Score (NPS) tanımları gerekmektedir.

- Üretim, haberleşme, pazarlama ve personel giderlerinin, müşteriye değer teklifleri sunulması esnasında gerçek zamanlı / on-line etkisi hesaplanarak, fonlama ve sermaye maliyetlerinin bilanço ve gelir tablosu üzerindeki etkileri gerçek zamanlı görülebilecektir. Bu şekilde bilnaçodaki çeşitli riskleri daha kolay yönetmek mümkün olacaktır.

- Satış ve teslimat saatlerindeki esneklikler ile şirketlerin müşterilerine ulaştığı dağıtım kanallarındaki robotik, drone gibi yeni teknolojiler şirketleri daha verimli ve kârlı çalışmaya yöneltecektir.

- Hologram teknolojisi ile müşterilerle anında etkileşim sağlanabilecektir. Özellikle perakende sektöründe şirketlerde sağlanacak satış ve dağıtım maliyetleri azalacak, doğrudan müşteriye ulaşım imkanı e-posta, SMS gibi kavramların ötesine geçecek, herhangi sınırları kalmadan müşterilere ulaşmak mümkün olacaktır. Bu noktada, örneğin 01 Mayıs 2015 tarihi itibarı ile geçerlilik kazanan 6563 sayılı Elektronik Ticaretin Düzenlenmesi Kanunu kapsamında izinli elektronik ileti tanımlarının genişletilmesi ihtiyacı bulunmaktadır. Hologram teknolojisi, aynı zamanda müşteriler, personel ve yönetim kurulu toplantılarına hızlıca ulaşma ve kurumlar için yeni bir teslimat ve satış kanalı olabilir. (Murray \& Keevil, 2014). Hologram müşteri temsilcileri uygulamaları halihazırda ilk uygulamalarına New York ve Atatürk Hava Limanlarında başlamıştır (Aamoth, 2012). Benzer şekilde Japonya'da banka örneğinde robot müşteri temsilcisi uygulamaš başlamıştır (Fukase, 2015)

\section{SONUÇ}

Bu çalışmada, henüz bir çok kavram henüz hayata geçmediğinden veya yeni üzerinde çalışılmaya başlandığından, iş hayatında ve ekonomik anlamda burada yer alan hipotezler bir bilim kurgu senaryosu olarak izlenim doğurabilir. Bilim kurgu ile bilim arasındaki ilişkiye, uzay araştırmaları üzerine çalışan bilim adamları üzerinden bir güncel örnek vererek, bu kuramsal ve kavramsal çalışmamızı özetleyelim.

Florida'daki NASA Kennedy Uzay Üssü direktörü astronot Bob Cabana'nın, 80 ve 90'lı yıllarda televizyon Türkiye'de tek kanallı iken izlenen fenomen bilimkurgu dizisi Uzay Yolu (Star Trek) karakteri Vulkan'lı Mr. Spock'ı canlandıran Leonard Limoy'un 2015 yılının başlarında ölümü sonrasında, sosyal medyadaki NASA Facebook hesabı üzerinden yayımladığı, Mr. Spock'un uzay çalışmalarında NASA (çalışanları) olarak ulaşmak istedikleri iyi örnek ve gerekli vasıfları kendisinde birleştiren bir uzay adamı olarak gördüklerini özetleyen veda mesajı, bu makalemizdeki çalışmalarda bilim kurgudan bilime doğru hızla yaklaştığımızı gösteren paralel bir anlayışı temsil etmektedir. Uluslararası Uzay İstasyonu'ndaki astronotlardan Scott Kelly'in Amerika Birleşik Devletleri Başkanı Barack Obama ile sosyal medyada Twitter hesabı üzerinden yaptıkları yazışma teknolojinin uzaya doğru yönlendiğini gösteren önemli örneklerden biridir (Wagstaff, 2015). Keza, bu çalışmada yer alan tüm diğer teknolojik gelişmeler, robotlar, akıllı zeka, 3D yazıcılar gibi, 
nihai hedef olan uzaya yönelik destek trendlerdir. Apollo $13^{\prime}$ de yaşanan havalandırma sıkıntısının modüldeki kısıtlı alet ve teçhizatla çözümüne dair bir alternatiftir örneğin 3D yazıcılar. Keza, Mars'ta halihazırda dolaşan Curiosity aracı bir robottur ve henüz insanın gidemediği yerlerde onun adına çalışmaktadır. Birleşik Arap Emirlikleri'nin World Economic Forum (WEF) ile robotik ve yapay zeka için ortak çalışma konseyi kurduğunu ve dikkate aldığımızda bu günlere çok da uzak olmadığımızı son söz olarak önermek mümkün olacaktır.

Günümüzde mobil uygulamalar, sosyal medya, web bazlı yapay neural ağlardaki (artificial neural networks) pazarlama çalışmaları ile öncü göstergeleri deneyimlediğimiz süreçlerin, yakın gelecekte farklı formatlar üzerinden pazarlama başta olmak üzere müşteri davranışları, satışçılar, karar vericiler, pazarlama iletişim uzmanları üzerinde doğuracağı sonuçları bu çalışmamız ile özet olarak değerlendirmekteyiz.

Müşterileri banka şubelerinde karşılayan robotlar, sermaye piyasalarında yatırımların durumuna kendisi karar veren yazılımlar, askeri amaçla başlayan drone'ların ticari amaçlarla kullanılmaya başlaması, Google'ın insansız arabası, giyilebilir teknolojik ürünler, evdeki ısıtma ve soğutma sistemlerinin uzaktan çalıştırılması gibi günümüzde yaşanan örnekler sadece bir başlangıçtır. Müşteriler açısından dağıtım kanallarında kullanımından, kampanya yönetimi, analitik CRM gibi uygulamalara kadar bir çok alanda satıştan pazarlamaya kadar etkileri olacak bir dünyada, özellikle işgücüne doğrudan yapacağı etkiler şimdiden ekonomi ve iş sayfalarında ve akademik çalışmalarda yer almaya başlamaktadır. Pazarlama iletişimi, reklam, promosyon gibi alanlarda faydalarının ve dezavantajlarının benzer şekilde deneyimlenmesi sözkonusu olacaktır. Psikoloji ve sosyoloji bilim dallarında yine insan davranışlarının pazarlama boyutundan bu teknolojiler ile etkileşiminin irdelenmesi gerekliliği ön plana çıkacaktır.

Sonuç olarak, yukarıdaki paragraflarda özetlediğimiz bulgular ve tartışmalar göstermektedir ki, teknolojik gelişmeler, internet ve semantik uygulamalar, robotik / mekatronik gelişmeler ve yapay zekanın işletmelerde daha yoğun kullanımı ile Pazarlama bilim dalında çok farklı gelişmeler akademik ve profesyonel dünyada bizleri beklemektedir. Bu çalışmamız, bundan sonraki benzer konu başlıklarına bir baz teşkil edecek ve Pazarlama bilimi alt dallarına yönelik, bu çalışmada detaylı olarak incelenemeyen, özellikle CRM ve insan kaynağı, veri madenciliği üzerine detaylı analizlere kaynakça teşkil edecektir.

\section{KAYNAKÇA}

Aamoth, D. (2012), Hologram-like' Helpers Materializing at New York-Area Airports Soon, Time Dergisi, May 22, 2012, http://techland.time.com/2012/05/22/hologram-like-helpers-materializing-at-new-york-area-airportssoon/ (Erişim Tarihi : 25 Mayıs 2015)

Achrol, R.S., Kotler, P (1999), Marketing in the Network Economy, Journal of Marketing, Vol. 63, Fundamental Issues and Directions for Marketing : 146-163

Algaç, K. (2010), Kullanıcıya Göre Yükseklik Ayarı Yapabilen Mekatronik Tasarımlar ve Bir Uygulama Örneği, Yayınlanmamış Yüksek Lisans Tezi, Balıkesir : Balıkesir Üniversitesi, FBE.

Altan, M. \& Karasioğlu, F. (25-26 Kasım 2004). Internet Bankacılığının Toplum Katmanlarınca Kullanımı Üzerine Bir Araştırma. 3. Ulusal Bilgi, Ekonomi ve Yönetim Kongresi, Osmangazi Üniversitesi : 601-611. 
Amiri Aghdaie, S.F., Karimi, R. \& Abasaltian, A. (28 March 2015). The Evaluation of Effect Electronic Banking in Customer Satisfaction and Loyalty. International Journal of Marketing Studies; Vol. 7, No. 2. Canadian Center of Science and Education. ISSN 1918-719X E-ISSN 1918-7203.

Ardor, H., Varlık, S. (2012), Keynes'in Likidite Tercihi Kuramı'nda Finans Motifi ile Para Talebinin Önemi ve Etkileri. Ekonomik Yaklaşım 23.1 : 195-220.

Basel Committee on Banking Supervision. (2003). Risk Management Principles for Electronic Banking, Switzerland : Bank of International Settlements, 1-11. http://www.bis.org/publ/bcbs98.pdf (Erişim Tarihi: 19 Nisan 2015).

Baydur, C. M., Süslü, B. (2011), Likidite Tuzağı Altında Para ve Maliye Politikası: AB ve Türkiye Deneyimi, Optimal Monetary and Fiscal Policies Under Liquidity Trap: EU and Turkish Experience. Süleyman Demirel Üniversitesi İktisadi ve İdari Bilimler Fakültesi Dergisi, C.16, S.2 :13-38.

Bayrakdaroğlu, A.(2012). Bireylerin İnternet Bankacılığı Kullanımını Etkileyen Faktörlerin Belirlenmesi Üzerine Bir Alan Araştırması. Business and Economics Research Journal, V.3 No. 4, 57-75. ISSN: 1309-2448.

Brooks, R. A. (2002), Flesh And Machines: How Robots Will Change Us. New York: Pantheon Books.

Buiter, W. (May 2008). Can Central Banks Go Broke ? European Institute, LSE, Universiteit van Amsterdam and CEPR, Center for Economic Policy Research, Policy Insight No. 24, 10-11.

Enloe, L. H., Murphy, J. A., \& Rubinstein, C. B. (1966). Hologram transmission via television. Bell System Technical Journal, 45(2) : 335-339.

Faden, E.S. (2001), The Cyberfilm: Hollywood and Computer Technology, Strategies: Journal of Theory, Culture \& Politics, Volume 14, Issue 1 : 77-90

Federal Reserve Statistical Release, Factors Affecting Reserve Balances - H.4.1, http://www.federalreserve.gov/releases/h41/Current/ (Erişim Tarihi : 29 Mayıs 2015)

Fisunoğlu, M, Bilge K. T. (2009), Keynes Devrimi ve Keynesyen İktisat. Ekonomik Yaklaşım 20.7031-60.

Fukase, A. (2015), Pint-Size Humanoid Helps Customers at Japanese Bank, Wall Street Journal Gazetesi Bloğu, Japan Times, 14 April 2015 2:50 pm JST, http://blogs.wsj.com/iapanrealtime/2015/04/14/pint-size-robot-helpscustomers-at-japanese-bank/ (Erişim Tarihi : 29 Mayıs 2015)

Griffin, A. (Monday 12 January 2015), Stephen Hawking, Elon Musk And Others Call For Research To Avoid Dangers of Artificial Intelligence, http://www.independent.co.uk/life-style/gadgets-and-tech/news/stephenhawking-elon-musk-and-others-call-for-research-to-avoid-dangers-of-artificial-intelligence-9972660.html, (Erişim Tarihi : 29 Mayıs 2015)

HT Ekonomi. (28 Mayıs 2015 Perşembe, 13:51:15), Yunanistan'ın iflas riski yükseldi!. Habertürk Haber Sitesi, Anadolu Ajansı Haberi. http://www.haberturk.com/ekonomi/ekonomi/haber/1084161-yunanistanin-iflas-riskiyukseldi (Erişim Tarihi : 29 Mayıs 2015)

Howden, D. (3 September 2009). Can a Central Bank Go Broke ? Mises Institute Daily. https://mises.org/library/can-central-bank-go-broke (Erişim Tarihi: 19 Nisan 2015).

Kharpal, A. (6 Mayıs 2015 | 9:51 AM ET), Amazon's drones could follow you to work, CNBC Haber Kanalı Web Sitesi, http://www.cnbc.com/2015/05/06/patent-filing-lifts-lid-on-amazons-drone-delivery-plans.html (Erişim Tarihi : 29 Mayıs 2015)

Leuski, A. (2006), How to talk to a hologram?. Proceedings of the 11th International Conference on Intelligent User Interfaces. ACM.

Lewis, T. LiveScience.com (25 Şubat 2015), Stephen Hawking Thinks These 3 Things Could Destroy Humanity. http://www.livescience.com/49952-stephen-hawking-warnings-to-humanity.html (Erişim Tarihi : 25 Nisan 2015)

Lolli, F.M.A. (2013). Semantics and pragmatics in actual software applications and in web search engines: exploring innovations. CoRR abs/1307.0087 . http://arxiv.org/ftp/arxiv/papers/1307/1307.0087.pdf

Markoff, J. (2010), Google Cars Drive Themselves, in Traffic. New York Times 9 
Mas, I., \& Kumar, K. (June 2008). Banking on Mobiles: Why, How, for Whom ? Focus Note 48. Washington, D.C.: CGAP Publications.

Matthews, D. (2013), I, Robot: Can Artificial Inteligence Play A Role In Business Applications? : 20.

Murray, S.H., Keevil, A.A. (21 August 2014). System and Method for Interactive Virtual Banking, Patent, No : US 20140236740 A1.

Noel, C., Glazer, R. (1987), Marketing and Technology: A Strategic Coalignment. Journal of Marketing, Vol. 51, No.3 : 1-14

Phillips, A. (07 Ekim 2014), Volkswagen to replace human workforce with robots in Germany to meet demand. Manufacturing Global Magazine. http://www.manufacturingglobal.com/peopleskills/170/Volkswagen-toreplace-human-workforce-with-robots-in-Germany-to-meet-demand (Erişim Tarihi : 25 Nisan 2015)

Porter, M.E. (1985, republished 1998). Competitive Advantage: Creating and Sustaining Superior Performance, The Free Press, New York.

Roubini, N. (08 Aralık 2014), Rise of the Machines: Downfall of the Economy? http://www.roubinisedge.com/nouriel-unplugged/rise-of-the-machines-downfall-of-the-economy (Erişim Tarihi : 25 Nisan 2015)

Seyed Javadin, S. R., \& Yazdani, S. (2005). Factors Affecting The Intention Of Customers To Use Internet Banking Service (Case Study Saman Bank). Management Knowledge, 70, 45-61.

Singer, P. W. (2010), War of the Machines. Scientific American 303.1: 56-63.

Stiglitz, J.E. (Kasım 2014), Unemployment And Innovation. Working Paper 20670 http://www.nber.org/papers/w20670, National Bureau Of Economic Research 1050, s.3. (Erişim Tarihi : 25 Nisan 2015)

Tarhan, U. (Şubat 2010), Türkiye İşveren Sendikaları Konfederasyonu İşveren Dergisi. 5 : 26-29. http://tisk.org.tr/tr/e-dergiler/isveren/2010/subat/index.html (Erişim Tarihi : 25 Nisan 2015)

Taylor, J. G. (1993). The Promise of neural networks. Springer-Verlag New York, Inc.

Wagstaff, K. (03 Ağustos 2015), NASA Astronaut Scott Kelly Answers Twitter Questions from Space. NBC News Haber Web Sitesi, Science, Space. http://www.nbcnews.com/science/space/nasa-astronaut-scott-kelly-answerstwitter-questions-iss-n403071, (Erişim Tarihi : 06 Ağustos 2015)

World Economic Forum, Agenda, Artificial Intelligence and Robotics. https://agenda.weforum.org/topic/globalissues/future-of-the-internet/artificial-intelligence-and-robotics/ (Erişim Tarihi : 25 Nisan 2015) 